\title{
ВЛИЯНИЕ ДИСПЛАЗИИ СОЕДИНИТЕЛЬНОЙ ТКАНИ НА ГОРМОНАЛЬНЫЙ ФОН ДЕТЕЙ С ФУНКЦИОНАЛЬНОЙ ДИСПЕПСИЕЙ
}

\author{
(C) Почехонова Ю.В.
}

\author{
Кафедра пропедевтики педиатрии \\ Донецкого национального медицинского университета им. М. Горького, Донецк \\ E-mail: poshehonova@list.ru
}

\begin{abstract}
Обследовано 134 ребенка с функциональной диспепсией (ФД) в возрасте от 5 до 15 лет. Наличие стигм дисплазии соединительной ткани и дизэмбриогенеза было выявлено в фенотипе $88,0 \%$ детей с ФД, при этом 6 и более стигм отмечено у $31,3 \%$ пациентов, чаще при язвенноподобном варианте. Среднее количество стигм у ребенка с ФД составило $5,0 \pm 0,3$. У детей с ФД наблюдалась гиперинсулинемия, наиболее значительная при язвенноподобном и дискинетическом вариантах. Уровень кортизола в сыворотке крови у детей с ФД был в пределах нижней границы нормы, при этом гиперкортизолемия была характерна для больных язвенноподобным вариантом. У детей с множественными стигмами дисплазии соединительной ткани и дизэмбриогенеза выявлено пониженное содержание инсулина и кортизола в сыворотке крови. Вероятно, это может обусловливать более тяжелое течение ФД у детей данной группы с высоким риском трансформации ее в хроническую патологию гастродуоденальной зоны.
\end{abstract}

Ключевые слова: функциональная диспепсия, дети, дисплазия соединительной ткани, дизэмбриогенез, инсулин, кортизол.

\section{EFFECT OF CONNECTIVE TISSUE DYSPLASIA ON THE HORMONAL BACKGROUND OF CHILDREN WITH FUNCTIONAL DYSPEPSIA Poshehonova J.V.}

Department of Propedeutics of Pediatrics of M. Gorky Donetsk National Medical University, Donetsk

134 children with functional dyspepsia (FD) at the age from 5 to 15 years were examined. The presence of connective tissue dysplasia and dysembryogenesis stigmata was revealed in the phenotype of $88.0 \%$ of children with FD, 6 or more stigmas were observed in $31.3 \%$ of patients, most often in ulcer-like dyspepsia. The average number of stigmas in a child with FD was $5.0 \pm 0.3$. In children with FD hyperinsulinemia was observed, the most significant in ulcer-like and dysmotility-like dyspepsias. The level of cortisol in the blood serum in children with FD was within the lower limit of normal, while hypercortisolemia was typical for patients with ulcer-like dyspepsia. In children with multiple stigmas of connective tissue dysplasia and dysembryogenesis, a low content of insulin and cortisol in the blood serum was detected. Probably, this may cause a more severe course of FD in children of this group with a high risk of its transformation into the chronic pathology of the gastroduodenal area.

Keywords: functional dyspepsia, children, connective tissue dysplasia, dysembryogenesis, insulin, cortisol.

Лежащие в основе развития функциональной диспепсии (ФД) преходящие изменения желудочной секреции и моторики, нарушения функционирования сфинктерного аппарата желудка $[9,18$, 19, 21], некоторая неполноценность барьерных механизмов слизистой оболочки желудка (СОЖ) $[1,5]$ могут быть обусловлены особенностями синтеза слизи, гликопротеидов и других мукополисахаридов. Эти изменения, возможно, связаны с генетически обусловленными особенностями метаболизма соединительной ткани, которые имеются у лиц с дисплазией соединительной ткани (ДСТ) [2, 6, 7, 8, 10, 14, 15, 17]. С другой стороны, важную роль в регуляции секреции, моторики и чувствительности рецепторов желудка помимо нейрогуморальной системы играют также такие гормоны как инсулин и кортизол [4, 5]. Кортизол стимулирует базальную фазу желудочной секреции с усиленным отделением соляной кислоты и пепсина при незначительном снижении секреции слизи СОЖ, изменяет чувствительность рецепторов желудка, влияя на функциональное состояние ЦНС и ВНС. Инсулин также стимулирует желудочную секрецию, вызывает двухфазную двигательную реакцию с периодом начального угнетения с последующим возбуждением моторики гастродуоденальной зоны. Особенности роста и развития детей в современных условиях экологически неблагоприятной обстановки в совокупности с длительными алиментарными погрешностями сопровождаются не только изменениями в содержании в крови инсулина и кортизола, но и высокой частотой ДСТ в детской популяции $[7,8,10]$. Последняя, являясь полигенным синдромом с мутацией гена фибриллина либо наличием аномальных форм коллагена и нарушения соотношения разных групп коллагенов, дефектами мукополисахаридов и гликопротеидов, оксипролина и др., приводит не только к нарушению формообразования и дифференцировке различных отделов ЖКТ $[11,13,20]$, но и к изменениям вегетативного и гормонального регулирова- 
ния, которое может повлиять на реализацию у ребенка ФД [6, 7]. Вопрос о частоте ДСТ у детей, больных ФД, как и содержание в крови кортизола и инсулина, недостаточно освещен, хотя это необходимо для выяснения механизмов формирования ФД и более углубленного обследования этих детей с целью оптимального лечения и предотвращения реализации ФД в воспалительные процессы гастродуоденальной зоны.

Целью данной работы было выявление стигм ДСТ и дизэмбриогенеза (ДЭ) и исследование уровней кортизола и инсулина в сыворотке крови детей с ФД, поскольку эти факторы могут принимать участие в патогенезе данной функциональной патологии.

\section{МАТЕРИАЛЫ И МЕТОДЫ ИССЛЕДОВАНИЯ}

Нами обследовано 134 ребенка с диагнозом ФД в возрасте от 5 до 15 лет, составивших основную группу, и 30 здоровых детей-сверстников, составивших контрольную группу. Диагностика ФД проводилась в соответствии с Римскими критериями III, адаптированными для детского возраста $[3,12,16,18,19]$. Всем детям проведено комплексное общепринятое клинико-инструментальное обследование, включающее фиброэзофагогастродуоденоскопию (ФЭГДС), одномоментную внутрижелудочную рН-метрию, уреазный тест, УЗИ печени, желчного пузыря и поджелудочной железы, ЭхоКГ, ирригографию (по показаниям), общепринятое лабораторное обследование (общие анализы крови, мочи и кала).

Поскольку для суждения о наличии ДСТ пользуются выявлением внешних проявлений, у всех детей оценивался не только характер, но и количество стигм ДСТ. Изучалось наличие следующих стигм ДСТ: астеническое телосложение, нарушение осанки, деформации позвоночника, грудины, ребер, гипермобильность суставов, плоскостопие, гиперэластичность кожи, пигментные пятна, миопия, косоглазие, грыжи, расширение вен. Выявляемые во время инструментального обследования птозы внутренних органов, пролапсы клапанов сердца также рассматривались как проявления ДСТ. Вариантом анатомической нормы считалось наличие 1-2 стигм ДСТ. Но наличие 3 и более стигм ДСТ, особенно в сочетании с аномалиями внутренних органов и пролапсами клапанов сердца, расценивалось как синдром ДСТ. Известно, что наличие синдрома ДСТ во внутриутробном периоде может приводить к формированию микроаномалий развития. Поэтому изучалось наличие и количество у детей таких стигм ДЭ, как аномалии развития черепа, лица, глаз, ушей, рта, кистей и стоп, а также микроаномалии внутренних органов при инструментальном обследовании. Вариантом анатомической нормы считалось наличие 0-3 стигм ДЭ.
Количественное содержание кортизола в сыворотке крови натощак определялось методом твердофазного иммуноферментного анализа с использованием набора реактивов «СтероидИФАкортизол». Результаты выражали в нмоль/л. При определении уровней кортизола в сыворотке крови детей контрольной группы содержание последнего недостоверно увеличивалось с $375 \pm 22,4$ нмоль/л у детей 5-7 лет до $408,7 \pm 28,0$ нмоль/л и 452,5 $\pm 39,4$ нмоль/л у детей 7,5-10,5 и 11-15 лет соответственно. Поэтому в дальнейшем для сравнения использовались средние нормальные показатели кортизола $420,5 \pm 30,5$ нмоль/л.

Определение содержания инсулина натощак проводилось иммуноферментным методом с использованием стандартного коммерческого набора реактивов DRG Instruments $\mathrm{GmBH}$ (Германия). Результаты выражались в мМЕ/л. При определении уровней инсулина в сыворотке крови детей контрольной группы содержание последнего недостоверно изменялось: 7,5 $\pm 2,5 \mathrm{MME} / л$ у детей 5-7 лет; 6,2 2 ,6 мМЕ/л у детей 7,5-10,5 лет; $9,7 \pm 2,8$ мМЕ/л у детей 11-15 лет. Поэтому в дальнейшем для сравнения использовались средние нормальные показатели инсулина 7,8 $\pm 1,7 \mathrm{мME/л.}$

Статистическая обработка полученных данных проводилась методами вариационной статистики с использованием параметрических методов. Статистическая достоверность производных и средних величин оценивалась по критерию Стьюдента, достоверным считалось значение, вероятность ошибки которого составляла 5\% $(\mathrm{p} \leq 0,05)$. Математическая обработка материала осуществлялась с использованием лицензированного пакета программ Microsoft Excel 2000 (9.0.3821 SP-1).

\section{РЕЗУЛЬТАТЫ ИССЛЕДОВАНИЯ И ИХ ОБСУЖДЕНИЕ}

У обследуемых детей во все возрастные периоды преобладал дискинетический вариант ФД (ДВФД) (64 ребенка 47,8 $\pm 4,3 \%$ ) (рис. 1), реже встречался неспецифический вариант (НВФД) (46 детей, $34,3 \pm 4,1 \%$ ).

Частота язвенноподобного варианта (ЯВФД) была почти в 3 раза меньше, чем ДВФД (24 ребенка, $18,0 \pm 3,3 \%, \mathrm{p} \leq 0,02)$, но с возрастом она увеличивалась с $10,5 \pm 7,0 \%$ у детей $5-7$ лет до $27,1 \pm 5,8 \%$ у подростков $(\mathrm{p} \leq 0,05)$.

Наличие стигм ДСТ и ДЭ было выявлено в фенотипе $88,0 \pm 2,8 \%$ детей с ФД: до 5 стигм имели $56,7 \pm 4,3 \%$ больных, 6 и более стигм - 31,3 $4,0 \%$ пациентов, в том числе 10 и более стигм было отмечено у $6,0 \pm 2,1 \%$ детей (табл. 1). Среднее количество стигм ДСТ и ДЭ у одного ребенка с ФД составило $5,0 \pm 0,3$. Из проявлений ДСТ и ДЭ чаще всего выявлялись следующие: деформация 


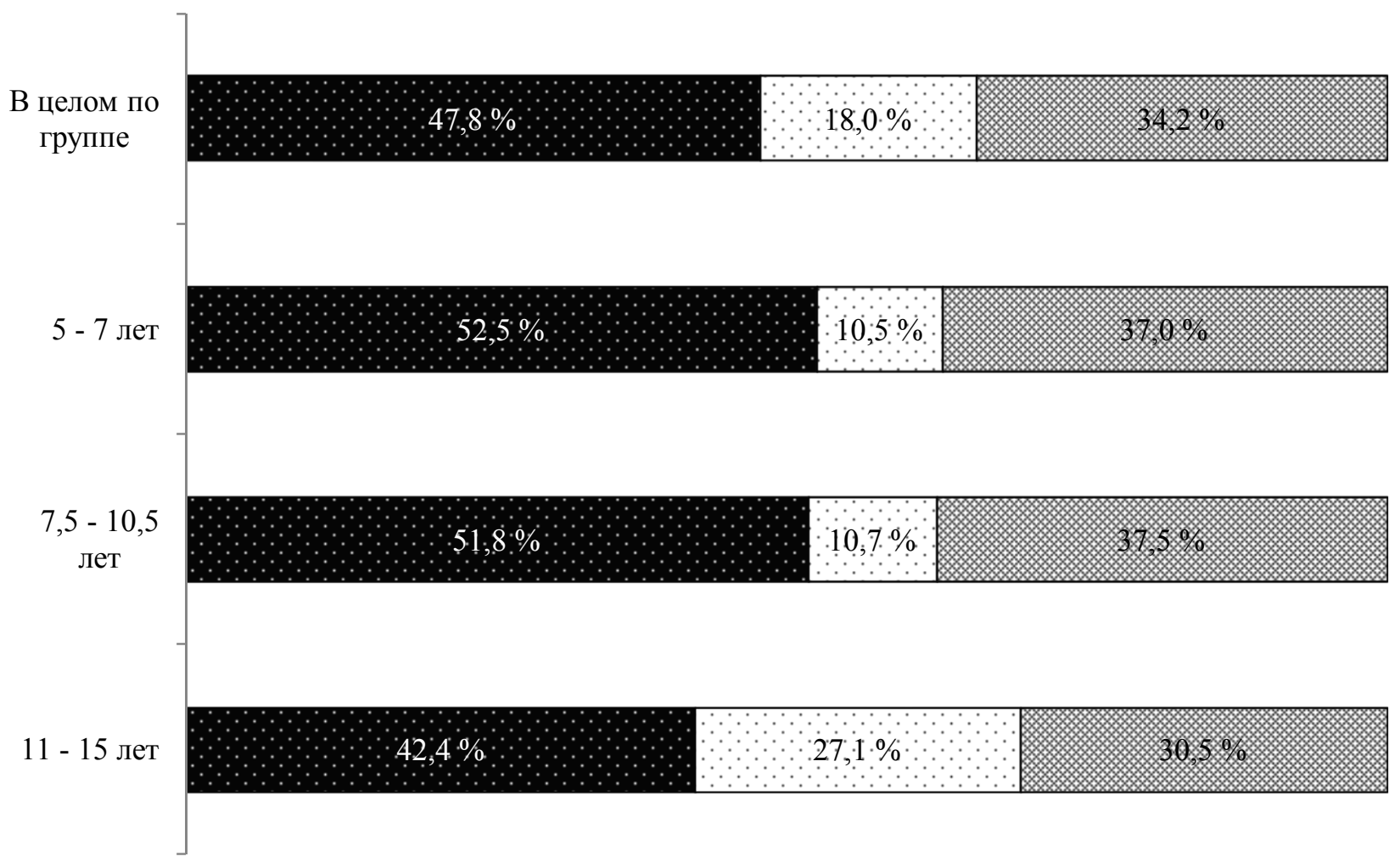

Дискинетический вариант घЯзвенноподобный вариант

Рис. 1. Частота клинических вариантов ФД у детей разного возраста.

Частота стигм ДСТ и ДЭ у детей с ФД

Таблица 1

\begin{tabular}{|l|c|c|c|c|c|}
\hline $\begin{array}{c}\text { Группы } \\
\text { детей }\end{array}$ & $\begin{array}{c}\text { Всего детей, } \\
\text { имевших стигмы, } \\
\mathrm{M} \pm \mathrm{m}, \%\end{array}$ & $\begin{array}{c}1-5 \text { стигм, } \\
\mathrm{M} \pm \mathrm{m}, \%\end{array}$ & $\begin{array}{c}\text { 6 и более } \\
\text { стигм, } \\
\mathrm{M} \pm \mathrm{m}, \%\end{array}$ & $\begin{array}{c}10 \text { и более } \\
\text { стигм, } \\
\mathrm{M} \pm \mathrm{m}, \%\end{array}$ & $\begin{array}{c}\text { Среднее количество } \\
\text { стигм у одного ребенка, } \\
\mathrm{M} \pm \mathrm{m}\end{array}$ \\
\hline ФД $(\mathrm{n}=134)$ & $88,0 \pm 2,8$ & $56,7 \pm 4,3$ & $31,3 \pm 4,0$ & $6,0 \pm 2,1$ & $5,0 \pm 0,3$ \\
\hline ДВФД $(\mathrm{n}=64)$ & $84,4 \pm 4,5$ & $53,1 \pm 6,2$ & $31,3 \pm 5,8$ & $6,3 \pm 3,0$ & $5,0 \pm 0,4$ \\
\hline ЯВФД $(\mathrm{n}=24)$ & $95,8 \pm 4,1$ & $50,0 \pm 10,2$ & $45,8 \pm 10,2$ & $4,2 \pm 4,2$ & $5,3 \pm 0,6$ \\
\hline $\mathrm{p}_{1}$ & 0,05 & 0,4 & 0,2 & 0,7 & 0,7 \\
\hline НВФД $(\mathrm{n}=46)$ & $89,1 \pm 4,6$ & $65,2 \pm 7,0$ & $24,0 \pm 6,3$ & $6,5 \pm 3,6$ & $4,8 \pm 0,5$ \\
\hline $\mathrm{p}_{2}$ & 0,5 & 0,1 & 0,4 & 1,0 & 0,8 \\
\hline $\mathrm{p}_{3}$ & 0,3 & 0,05 & 0,05 & 0,6 & 0,5 \\
\hline
\end{tabular}
ЯВФД.

Примечание: $\mathrm{p}_{1}$ - по сравнению с больными ДВФД; $\mathrm{p}_{2}$ - по сравнению с больными ДВФД; $\mathrm{p}_{3}-$ по сравнению с больными

позвоночника $(53,0 \pm 4,3 \%)$, астеническое телосложение $(51,5 \pm 4,3 \%)$, аномалии развития ушных раковин $(46,3 \pm 4,3 \%)$ и стоп $(22,4 \pm 3,6 \%)$, гипермобильность суставов $(21,6 \pm 3,6 \%)$, аномалии развития кистей $(19,4 \pm 3,4 \%)$, аномалии положения толстого кишечника $(20,2 \pm 3,5 \%)$, гиперэластичность кожи $(15,7 \pm 3,1 \%), \quad$ брахицефалия $(15,7 \pm 3,1 \%)$, плоскостопие $(15,0 \pm 3,1 \%)$, пролапс митрального клапана $(13,4 \pm 3,0 \%)$.

Хотя количество стигм у одного ребенка при различных клинических вариантах ФД достоверно не отличалось, при ЯВФД 95,8 $44,1 \%$ детей имели проявления ДСТ и ДЭ, тогда как при ДВФД и НВФД они были выявлены соответ- ственно у $84,4 \pm 4,5 \%(\mathrm{p} \leq 0,05)$ и $89,1 \pm 4,6 \%(\mathrm{p} \leq 0,3)$ детей.

При этом до 5 стигм ДСТ и ДЭ чаще встреча-

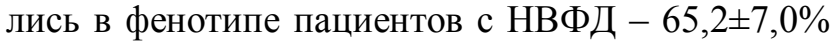
(ЯВФД - 50,0 $\pm 10,2 \%, p \leq 0,05$, ДВФД - 53, $1 \pm 6,2 \%$, $\mathrm{p} \leq 0,1)$. Наличие 6 и более стигм ДСТ и ДЭ чаще имели дети с ЯВФД - 45,8 $10 \%$ (ДВФД $31,3 \pm 5,8 \%, \mathrm{p} \leq 0,2$, НВФД - 24,0 $\pm 6,3 \%, \mathrm{p} \leq 0,05)$.

Гормональный фон у детей с ФД характеризовался тем, что средний уровень инсулина в сыворотке крови у них превышал показатели здоровых детей из группы контроля $(16,4 \pm 1,6 \mathrm{MME} / л$, $\mathrm{p} \leq 0,02)$, тогда как содержание в сыворотке крови кортизола было в пределах нижней границы 
Уровни инсулина и кортизола в сыворотке крови детей с ФД

\begin{tabular}{|c|c|c|}
\hline Группы детей & $\begin{array}{c}\text { Инсулин (в МЕ/л), } \\
\text { М } \pm \mathrm{m}\end{array}$ & $\begin{array}{c}\text { Кортизол (в нмоль/л), } \\
\mathrm{M} \pm \mathrm{m}\end{array}$ \\
\hline Здоровые дети $(\mathrm{n}=30)$ & $7,8 \pm 1,7$ & $420,5 \pm 40,5$ \\
\hline $\begin{array}{l}\text { Больные ФД }(\mathrm{n}=134) \\
\mathrm{p}\end{array}$ & $\begin{array}{c}16,4 \pm 1,6 \\
0,02\end{array}$ & $\begin{array}{c}368,1 \pm 35,2 \\
0,4\end{array}$ \\
\hline $\begin{array}{ll}\text { Клинические варианты ФД: } \\
\text { ДВФД }(\mathrm{n}=64) ; \\
\mathrm{p} \\
\text { ЯВФД }(\mathrm{n}=24) \\
\mathrm{p} \\
\mathrm{p}_{1} \\
\text { НВФД }(\mathrm{n}=46) \\
\mathrm{p} \\
\mathrm{p}_{1}\end{array}$ & $\begin{array}{c}17,3 \pm 1,6 \\
0,02 \\
17,5 \pm 1,5 \\
0,02 \\
1,0 \\
14,0 \pm 1,1 \\
0,05 \\
0,2\end{array}$ & $\begin{array}{c}288,1 \pm 10,8 \\
0,02 \\
510,3 \pm 25,8 \\
0,1 \\
0,01 \\
310,3 \pm 35,9 \\
0,05 \\
0,7\end{array}$ \\
\hline 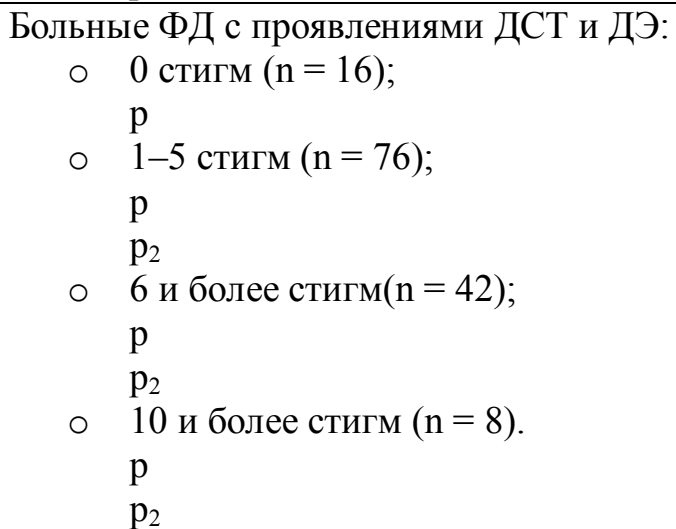 & $\begin{array}{c}16,0 \pm 1,8 \\
0,02 \\
16,3 \pm 1,6 \\
0,02 \\
1,0 \\
16,7 \pm 1,7 \\
0,02 \\
1,0 \\
7,8 \pm 1,1 \\
1,0 \\
0,02\end{array}$ & $\begin{array}{c}355,0 \pm 35,7 \\
0,3 \\
362,8 \pm 33,5 \\
0,3 \\
0,9 \\
378,5 \pm 39,3 \\
0,5 \\
0,8 \\
263,7 \pm 29,1 \\
1,0 \\
0,02\end{array}$ \\
\hline
\end{tabular}

Примечание: $\mathrm{p}$ - по сравнению со здоровыми детьми; $\mathrm{p}_{1}$ - по сравнению с больными ДВФД; $\mathrm{p}_{2}$ - по сравнению с больными, не имеющими стигм ДСТ и ДЭ.

нормы $(368,1 \pm 35,2$ нмоль/л, $\mathrm{p} \leq 0,4)$ (табл. 2). Повышение уровней инсулина в крови (выше 11,2 мМЕ/л) имелось у 51,0\% больных ФД, 49,0\% детей с ФД имели нормальные уровни инсулина. Снижение уровня кортизола в сыворотке крови (ниже 339,5 нмоль/л) наблюдалось у 52,0\% больных ФД, у 36,0\% детей содержание кортизола в крови было в пределах нормы. Повышенный уровень кортизола (выше 501,5 нмоль/л) был выявлен у $12,0 \%$ пациентов.

У больных различными клиническими вариантами ФД наблюдалась разная степень гиперинсулинемии. При ДВФД и ЯВФД степень гиперинсулинемии была самой значительной и, практически, одинаковой (соответственно 17,3 $\pm 1,6$ нMЕ/л и 17,5 $\pm 1,5$ мМЕ/л), а у детей с НВФД последняя была менее выраженной $(14,0 \pm 1,1 \mathrm{MME} /$ л, $\mathrm{p} \leq 0,2)$. В то же время ЯВФД характеризовался не только значительной гиперинсулинемией, но и гиперкортизолемией $(510,3 \pm 25,8$ нмоль/л, $\mathrm{p} \leq 0,1)$, тогда как у больных ДВФД и НВФД уровни кортизола в сыворотке крови были достоверно снижены (соответственно $288,1 \pm 10,8$ нмоль/л, $\mathbf{p}<0,02$ и $310,3 \pm 35,9$ нмоль/л, $\mathrm{p}<0,05)$.

Наличие множественных стигм ДСТ и ДЭ у детей с ФД сочеталось со снижением уровней кортизола $\left(263,7 \pm 29,1\right.$ нмоль/л, $\left.\mathrm{p} \leq 0,02, \mathrm{p}_{4} \leq 0,05\right)$, и инсулина $\left(7,8 \pm 1,1 \mathrm{mME} / л, \mathrm{p}_{4} \leq 0,02\right)$ в сыворотке крови. В то же время у пациентов, не имевших или имевших до 10 стигм ДСТ и ДЭ, показатели кортизола и инсулина соответствовали показателям по группе детей с ФД.

Следовательно, у детей с ФД наблюдается достоверная гиперинсулинемия при тенденции к снижению кортизола в крови. Более выраженная гиперинсулинемия при гиперкортизолемии была выявлена у больных ЯВФД. Снижение уровня кортизола в сыворотке крови при выраженной гиперинсулинемии наблюдалось у больных ДВФД и НВФД. У детей с ФД и множественными стигмами ДСТ и ДЭ уровень кортизола в крови был достоверно снижен при нормальном содержании инсулина.

Таким образом, фенотип детей с ФД характеризовался наличием $5,0 \pm 0,3$ стигмы ДСТ и ДЭ в виде астенического телосложения, деформации позвоночника, гипермобильности суставов, гиперэластичности кожи, аномалий развития ушных раковин, кистей и стоп, плоскостопия, пролапса митрального клапана, брахицефалии.

У детей с ФД наблюдалась гиперинсулинемия, наиболее значительная степень которой от- 
мечена у больных с ЯВФД и ДВФД. И только у лиц с множественными стигмами ДСТ и ДЭ выявлено пониженное содержание инсулина в сыворотке крови. Уровень кортизола в сыворотке крови у детей с ФД был в пределах нижней границы нормы с тенденцией к еще боле, выраженному снижению у больных со множественными стигмами ДСТ и ДЭ. Это может обусловливать более тяжелое течение ФД у детей данной группы и высоким риском трансформации функциональных нарушений желудочной секреции и моторики в хроническую патологию гастродуоденальной зоны.

\section{ЛИТЕРАТУРА / REFERENCES}

1. Арсентьев В.Г., Арзуманова Т.И., Асеев М.В., Баранов В.С., Калядин С.Б., Никифорова И.Д., Шабалов Н.П. Полиорганные нарушения при дисплазиях соединительной ткани у детей и подростков // Педиатрия. Журнал им. Г.Н. Сперанского. 2009. - T. 87, № 1. - C. 137-138. [Arsent'yev V.G., Arzumanova T.I., Aseyev M.V., Baranov V.S., Kalyadin S.B., Nikiforova I.D., Shabalov N.P. Polyorganic disorders in dysplasia of connective tissue in children and adolescents. Pediatriya. Zhurnal im. G.N. Speranskogo. 2009; 87(1): 135-138 (in Russ.)].

2. Ахмедли К.Н. Особенности дефицита макро- и микроэлементов при дисплазии соединительной ткани // Современная педиатрия. - 2017. - Т. 4, № 84. - $\quad$ - C. $\quad$ C. 117-119. $\quad$. $\quad$ DOI: 10.15574/SP.2017.84.117. [Akhmedly K. The features of macro- and micronutrients deficiency in the connective tissue dysplasia Sovremennaya pediatriya. 2017; 4(84): 117-119 (in Russ.)].

3. Белоусов Ю.В., Белоусова О.Ю. Функциональные заболевания пищеварительной системы у детей. Харьков : ИД «ИНЖЕК», 2005. 252 c. [Belousov Yu.V., Belousova O.Yu. Functional diseases of the digestive system in children. Kharkiv : ID "INZHEK"; $2005: 256$ (in Russ.)].

4. Буторина Н.В., Запруднов А.М., Вахрушев Я.М. Гормональные нарушения у детей с гастроэзофагеальной рефлюксной болезнью // Российский вестник перинатологии и педиатрии. - 2013. T. 58, № 5. - C. 59-64. [Butorina N.V., Zaprudnov A.M., Vakhrushev Ya.M. Hormonal disorders in children with gastroesophageal reflux disease. Rossiyskiy vestnik perinatologii i pediatrii. 2013; 58(5): 59-64 (in Russ.)].

5. Буторина Н.В., Вахрушев Я.М., Запруднов А.М. Роль ряда гормонов и состояния обмена коллагена в патогенезе гастроэзофагеальной рефлюксной болезни у детей // Казанский медицинский журнал. 2014. - T. 95, № 1. - C. 54-58 [Butorina N.V., Vakhrushev Ya.M., Zaprudnov A.M. Influence of some hormones and collagen metabolism on gastroesophageal reflux disease pathogenesis in children. Kazanskiy meditsinskiy zhurnal. 2014; 95(1): 54-58 (in Russ.)].

6. Евтушенко С.К., Сохань Д.А., Морозова Т.М., Евтушенко Л.Ф., Шестова Е.П., Евтушенко О.С.,
Савченко E.A. Сочетанная дисплазия мозга и сердца у детей с церебральным параличом и ее влияние на реабилитационный процесс // Международный неврологический журнал. - 2014. - Т. 65, № 3. - C. 154-156. [Evtushenko S.K., Sokhan' D.A., Morozova T.M., Evtushenko L.F., Shestova E.P., Evtushenko O.S., Savchenko E.A. Combined dysplasia of the brain and heart in children with cerebral palsy and its impact on the rehabilitation process. Mezhdunarodnyy nevrologicheskiy zhurnal. 2014; 65(3): 154156 (in Russ.)].

7. Евтушенко С.К., Лисовский Е.В., Евтушенко О.С. Дисплазия соединительной ткани в неврологии и педиатрии. Руководство для врачей. - Донецк : ИД «Заславский», 2009. - 361 с. [Evtushenko S.K., Lisovskiy E.V., Evtushenko O.S. Dysplasia of connective tissue in neurology and pediatrics. A guidelines for doctors. - Donetsk : PH «Zaslavsky»; 2009: 361 (in Russ.)].

8. Земцовский Э.В. Недифференцированные дисплазии соединительной ткани. Попытка нового осмысления концепции // Медицинский вестник Северного Кавказа. - 2008. - № 2. - С. 8-14. [Zemtsovsky E.V. Nondifferentiated connective tissue dysplasia. Attempt of new judgement of the concept. Meditsinskiy vestnik Severnogo Kavkaza. 2008; (2): 8-14 (in Russ.)] .

9. Ивашкин В.Т., Шептулин А.А., Лапина Т.Л., Картавенко И.М., Киприанис В.А., Охлобыстина О.3., Новожилов Н.В. Рекомендации Российской гастроэнтерологической ассоциации по диагностике и лечению функциональной диспепсии // Российский журнал гастроэнтерологии, гепатологии, колопроктологии. - 2012. - Т. 22, № 3. - С. 80-92. [Ivashkin V.T., Sheptulin A.A., Lapina T.L., Kartavenko I.M., Kiprianis V.A., Okhlobystina O.Z., Novozhilov N.V. Guidelines of the Russian gastroenterological association on diagnostics and treatment of functional dyspepsia. Rossiyskiy zhurnal gastroenterologii, gepatologii, koloproktologii. 2012; 22(3): 80-92 (in Russ.)].

10. Кадурина Т.И., Горбунова В.Н. Дисплазия соединительной ткани. Руководство для врачей. СПб. : Элби-СПб, 2009. - 704 с. [Kadurina T.I., Gorbunova V.N. Dysplasia of connective tissue. Guidelines for doctors. - St.P. : Elbi-SPb; 2009: 704 (in Russ.)].

11. Комарова Е.В., Потапов А.С., Журкова Н.В., Кондакова О.Б. Дисплазия соединительной ткани как одна из причин возникновения хронических запоров у детей // Вопросы современной педиатрии. - 2007. - Т. 6, № 3. - С. 114-115. [Komarova Ye.V., Potapov A.S., Zhurkova N.V., Kondakova O.B. Connective tissue dysplasia as a cause of chronic constipation in children. Voprosy sovremennoy pediatrii. 2007; 6(3): 114-115 (in Russ.)].

12. Краснова E.E., Чемоданов В.В. Функциональная диспепсия и дифференцированный подход к ее лечению у детей // Вестник Ивановской медицинской академии. - 2009. - Т. 14, № 3. - С. 30-34. [Krasnova E.E., Chemodanov V.V. Functional dyspepsia and differential approach to its treatment in 
chidren. Vestnik Ivanovskoy meditsinskoy akademii. 2009; 14(3): 30-34 (in Russ.)].

13. Нестеренко 3.В. Преобразование структуры органов и тканей человека // Здоровье ребенка. 2010. - T. 25, № 4. - C. 136-139. [Nesterenko Z.V. Transformation of human organs and tissues structures. Zdorov'ye rebenka. 2010; 25(4): 136-139 (in Russ.)].

14. Российские национальные рекомендации. Наследственные нарушения структуры и функции соединительной ткани. - М., 2009. - 66 с. [Russian national recommendations. Hereditary disorders of the structure and function of connective tissue. - M.; 2009: 66 (in Russ.)].

15. Чурилина А.В., Москалюк О.Н., Чалая Л.Ф., Якубенко Е.Д., Эрлихман К.М. К вопросу о роли магния в формировании дисплазии соединительной ткани // Здоровье ребенка. - 2010. - Т. 26, № 5. C. 97-100. [Churilina A.V., Moskalyuk O.N., Chalaya L.F., Yakubenko Ye.D., Erlikhman K.M. The role of magnesium in connective tissue dysplasia forming. Zdorov'ye rebenka. 2010; 26(5): 97-100 (in Russ.)].

16. Эрдес С.И., Мухаметова Е.М., Петухова Е.В., Маиукатова Б.О. Дифференцированный подход к лечению детей с моторными и секреторными нарушениями верхних отделов пищеварительного тракта // Русский медицинский журнал. - 2010. -
T. 18, № 1. - C. 1-7. [Erdes S.I., Mukhametova E.M., Petukhova E.V., Matsukatova B.O. A differentiated approach to the treatment of children with motor and secretory disorders of the upper digestive tract. Russkiy meditsinskiy zhurnal. 2010; 18(1): 1-7 (in Russ.)].

17. Bravo J.F., Wolff C. Clinical study of hereditary disorders of connective tissues in a Chilean population: joint hypermobility syndrome and vascular EhlersDanlos syndrome. // Arthritis Rheum. - 2006. Vol. 54, N 2. - P. 515-523. - DOI: 10.1002/art.21557.

18. Drossman D.A. The functional gastrointestinal disorders and the Rome III process // Gastroenterology. 2006. - Vol. 130, N 5. - P. 1377-1390. - DOI: 10.1053/j.gastro.2006.03.008.

19. Drossman D.A. Rome III: The functional gastrointestinal disorders - Degnon Associates. Inc. - 3rd ed. 2006. - 1048 p.

20. Reilly D.J., Chase J.W., Hutson J.M., Clarke M.C., Gibb S., Stillman B., Southwell B.R. Connective tissue disorder - a new subgroup of boys with slow transit constipation? // J Pediatr Surg. - 2008. - Vol. 43, N 6. $-\quad$ P. $1111-1114$. - $\quad$ DOI: 10.1016/j.pedsurg.2008.02.041.

21. Tack J., Talley N.J. Gastroduodenal disorders // Am. J. Gastroenterol. - 2010. - Vol. 105, N 4. - P. 757763. - DOI: 10.1053/j.gastro.2005.11.059. 